\title{
Effects of long-term warming and enhanced nitrogen and sulfur deposition on microbial communities in a boreal peatland
}

\author{
Magalí Martí ${ }^{1,2}$ Alexander Eiler ${ }^{3,4,5}$, Moritz Buck ${ }^{3}$, Stefan Bertilsson ${ }^{3}$, Waleed Abu Al- \\ Soud $^{6,7}$, Søren Sørensen ${ }^{6}$, Mats B. Nilsson ${ }^{8}$, Bo H. Svensson ${ }^{1}$
}

1 Department of Thematic Studies - Environmental Change, Linköping University, Linköping, Sweden

2 Department of Clinical and Experimental Medicine, Linköping University, Linköping, Sweden

3 Department of Ecology and Genetics, Limnology and Science for Life Laboratory, Uppsala University, Uppsala, Sweden

4 eDNA solutions, Environmental DNA and bioinformatics solutions, Mölndal, Sweden

5 Department of Biosciences, Center for BioGeoChemistry in the Anthropocene, Section for Aquatic Biology and Toxicology, University of Oslo, Oslo, Norway

6 Department of Biology, Section of Microbiology, University of Copenhagen, Copenhagen, Denmark

7 Department of Clinical Laboratory Sciences, Jouf University, Qurayyat, Saudi Arabia

8 Department of Forest Ecology \& Management, Swedish University of Agricultural Sciences, Umeå, Sweden

Corresponding author: Magalí Martí, magali.marti.genero@liu.se.

\section{Abstract}

With ongoing environmental change, it is important to understand ecosystem responses to multiple perturbations over long time scales at in situ conditions. Here, we investigated the individual and combined effects of 18 years of warming and enhanced nitrogen and sulfate deposition on peat microbial communities in a nutrient-poor boreal mire. The three perturbations individually affected prokaryotic community composition, where nitrogen addition had the most pronounced effect, and its combination with the other perturbations led to additive effects. The functional potential of the community, characterized by shotgun metagenomics, was strongly affected by the interactive effects in the combined treatments. The responses in composition were also partly reflected in the functional gene repertoire and in altered carbon turnover, i.e. an increase of methane production rates as a result of nitrogen addition and a decrease with warming. Long-term nitrogen addition and warming-induced changes caused a shift from Sphagnum-dominated plant communities to vascular plant dominance, which likely transact with many of the observed microbial responses. We conclude that simultaneous perturbations do not always lead to synergistic effects, but can also counteract and even neutralize one another, and thus must be studied in combination when attempting to predict future characteristics and services of peatland ecosystems.

Keywords Microbial diversity, 16S rRNA, metagenome, peatland, climate change, nitrogen 


\section{Introduction}

Despite key roles of microbial communities in controlling carbon and nutrient dynamics within ecosystems, few studies have addressed effects of multiple drivers (e.g. anthropogenic stressors) on microbial taxonomic diversity and the associated genome-encoded traits underpinning realized ecosystem services (cf. Castro et al. 2010, Li et al. 2013, Andresen et al. 2014, Shen et al. 2014, Contosta et al. 2015). Given the multitude of human-derived disturbances, including climate change and atmospheric deposition of anthropogenic emissions, it is important to understand microbial community responses to multiple and parallel changes in the environment. Microorganisms will potentially react to such external impacts by shifting their community composition and function. This may lead to ecosystem structure repercussions causing feedbacks on e.g. the climate system via changes in greenhouse gas turnover and other ecosystem-scale processes. However, altered ecosystem services resulting from microbial community shifts may also be attenuated by functional redundancy within the community, assuming that many species are able to mediate the same functions in the ecosystem (Lawton \& Brown 1993, Nielsen et al. 2011, Tully et al. 2018). Microbial metabolism is central for most ecosystem services due to its central role in the turnover of essential nutrients and biogeochemical cycles (Martiny et al. 2015). For example, changes in the abundance of key microbial taxa able to produce or oxidize methane will influence the rate of methane emissions from various ecosystems that feature relevant redox conditions (McCalley et al. 2014). It is now tractable to characterize such genome-encoded functional traits with community-scale metagenome sequencing.

In situ manipulation experiments are well suited to test the responses of ecosystems and their microbial communities to various disturbance scenarios. Except for long-running trials in agricultural and forestry systems (Ramirez et al. 2010, Fierer et al. 2012, Leff et al. 2015, Zhou et al. 2015, Boot et al. 2016, Zeng et al. 2016), generally, in situ manipulations of soil 
ecosystems have mainly been conducted over short- to intermediate-length time periods, e.g. between 1 to 5 years. Thus, several such short time field studies on effects of nitrogen amendment and warming on diversity, function and abundance of microbial communities have been reported (Castro et al. 2010, Li et al. 2013, Andresen et al. 2014, Shen et al. 2014, Contosta et al. 2015). Yet, to identify environmental responses over ecologically relevant timescales, while at the same time accounting for short-term disturbance effects, long-term (at least decadal) field experiments are needed (Rinnan et al. 2007, Eriksson et al. 2010a, Contosta et al. 2015). Moreover, as all ecosystems are influenced by multiple stressors, we need to understand how interactive effects of multiple effectors (synergistic or antagonistic perturbations) influence microbial communities if we are to robustly predict ecosystem responses to global warming, changes in atmospheric nutrient deposition and anthropogenic pollution in general.

Ever since the last de-glaciation, northern peatlands have played an important role in the global carbon balance, and are currently estimated to hold $30 \%$ of the global soil carbon, i.e. carbon stocks estimated at 270 - 600 Pg of organic C (Gorham 1991, Turunen et al. 2002, Yu 2012). Due to slow rates of microbial decomposition, there is an imbalance between primary production and degradation in these ecosystems. Thus, undisturbed peatlands are generally contemporary net sinks of carbon dioxide $\left(\mathrm{CO}_{2}\right)$, while at the same time being significant sources of methane $\left(\mathrm{CH}_{4}\right)$ to the atmosphere (Roulet et al. 2007, Nilsson et al. 2008, Turetsky et al. 2014). Therefore, the impact of the predicted global climate change and atmospheric nitrogen $(\mathrm{N})$ and sulfate $(\mathrm{S})$ deposition on the peatland net ecosystem carbon balance (NECB) is a topic of major concern (Granberg et al. 2001, Galloway et al. 2004, Gauci et al. 2004, Phoenix et al. 2012).

Increased $\mathrm{N}$ availability is known to strongly affect plant species composition and performance of different plant functional types in peatlands (Damman 1988, Bridgham et al. 
1996, Eppinga et al. 2010, Limpens et al. 2011) as $\mathrm{N}$ is often a limiting nutrient (Wang \& Moore 2014). This is clearly demonstrated by the shift towards vascular plant-dominated vegetation in the long-term high $\mathrm{N}$ deposition experiment at Degerö Stormyr (Wiedermann et al. 2007, Eriksson et al. 2010a, Eriksson et al. 2010b). As a result, methane emissions increased in response to the enhanced $\mathrm{N}$ deposition (Eriksson et al. 2010b), whereas warming led to a decrease in methane production, oxidation and emissions (Eriksson et al. 2010a, Eriksson et al. 2010b).

It has been argued that novel mechanistic insights on biogeochemical dynamics can be obtained by studying peat microbial community composition and function, and that such information can further improve predictions of ecosystem responses to global change (Bragazza et al. 2015). To investigate the isolated and interactive effects of warming, $\mathrm{N}$ and $\mathrm{S}$ deposition on the peat microbial community and function, we applied high throughput sequencing approaches to peat samples collected after 18 years of continuous in situ field manipulation. We took advantage of a full factorial experimental design that was established at Degerö Stormyr in 1995 , consisting of nitrogen $\left(\mathrm{NH}_{4} \mathrm{NO}_{3}\right)$ and sulfate $\left(\mathrm{Na}_{2} \mathrm{SO}_{4}\right)$ amendments and warming (plots scale green-house covers) simulating the predicted effect of climate change (Granberg et al. 2001). Overall, simulated increased $\mathrm{N}$ deposition had the most pronounced effect on bacterial as well as archaeal communities. Multiple stressors interacted to give responses at the level of taxonomic and functional diversity, which influenced the functional potential of the ecosystem with regards to methane production, sulfate reduction, nitrate reduction and polymer hydrolysis. Thus, our experiment emphasizes the need to study the effects of climate change on microbial communities in the context of multiple environmental changes and anthropogenic-induced perturbations.

\section{Materials and Methods}




\section{Site description and peat samples collection}

124 Peat samples were collected from a full factorial experimental design in a Sphagnumdominated oligotrophic area at Degerö Stormyr, in North Sweden $\left(64^{\circ} 11^{\prime} \mathrm{N}, 19^{\circ} 33^{\prime} \mathrm{E}\right.$, altitude $270 \mathrm{~m}$ above sea level). Briefly, the experimental site is a boreal oligotrophic minerogenic mire, with a surface water $\mathrm{pH}$ of $\sim 4.5$. The climate of the reference period (1961-1990) was characterized by a mean annual precipitation of $523 \mathrm{~mm}$, a mean annual temperature of $1.2^{\circ} \mathrm{C}$, and a mean July and January temperatures of $14.7^{\circ} \mathrm{C}$ and $-12.4^{\circ} \mathrm{C}$, respectively. Average weather conditions during 2001-2012 were as follows (Peichl et al. 2014): annual and

131 growing season air temperatures $2.3^{\circ} \mathrm{C}$ and $11^{\circ} \mathrm{C}$, respectively, annual and growing season 132 precipitation of 666 and $395 \mathrm{~mm}$, respectively, and the growing season mean water table level at $14 \mathrm{~cm}$ below peat surface. The dominant vascular plants are Eriophorum vaginatum (L),

134 Andromeda polifolia (L). and Vaccinium oxycoccos $(L$.). The dominant moss species are established in 1995 (Granberg et al. 2001) and was conducted according to a full factorial experimental design including two levels of nitrogen $(\mathrm{N})$ i.e. ambient (low-level) at $2 \mathrm{~kg} \mathrm{~N}$ ha $^{-}$ ${ }^{1} \mathrm{yr}^{-1}$ and amendment (high-level) of $\mathrm{NH}_{4} \mathrm{NO}_{3}$ to reach a deposition at a level of $30 \mathrm{~kg} \mathrm{~N} \mathrm{ha}^{-1}$ $\mathrm{yr}^{-1}$, two levels of sulfur (S) i.e. ambient at $3 \mathrm{~kg} \mathrm{~S} \mathrm{ha}^{-1} \mathrm{yr}^{-1}$, and amendment of $\mathrm{Na}_{2} \mathrm{SO}_{4}$ to a level of $20 \mathrm{~kg} \mathrm{Sha}^{-1} \mathrm{yr}^{-1}$, and two levels of greenhouse (GH) treatment, i.e. high level GH

141 with a transparent cover or ambient (low level) of GH i.e. without a cover. Each experimental 142 combination was performed in duplicate. The elevated levels of $\mathrm{N}$ and $\mathrm{S}$ correspond to the 143 annual deposition amounts in southwest Sweden at the time for the start of the experiment.

144 For a detailed description of the site and experimental design see Granberg et al. (2001), and 145 for details on treatment effects on vegetation composition see Wiedermann et al. (2007). One 146 peat core $(0-40 \mathrm{~cm})$ was collected from each field plot $(\mathrm{n}=16)$ on August $14^{\text {th }}$ and $15^{\text {th }} 2013$.

147 From each core, $5 \mathrm{~cm}^{3}$ of peat were subsampled at five depths from below the Sphagnum 
surface: 7-11 cm (A), 11-15 cm (B), 15-19 cm (C), 19-23 cm (D) and 23-27 cm (E). The

149 samples were stored in $50 \mathrm{~mL}$ sterile tubes containing $2 \mathrm{~mL}$ of LifeGuard ${ }^{\mathrm{TM}}$ Soil Preservation

150 Solution (MoBio Laboratories, Hameenlinna, Finland), and kept at room temperature $\left(<20^{\circ} \mathrm{C}\right)$

151 for at most 24 hours before freezing at $-20^{\circ} \mathrm{C}$.

\section{Sample preparation}

154 Before extraction, peat samples were thawed over night at $4{ }^{\circ} \mathrm{C}$ and centrifuged at $2500 \mathrm{xg}$ for

$1555 \mathrm{~min}$. Total RNA and DNA were co-isolated from $2 \mathrm{~g}$ wet peat and recovered in $50 \mu \mathrm{l}$ using

156 the RNA PowerSoil ${ }^{\circledR}$ Total RNA Isolation Kit together with the RNA PowerSoil ${ }^{\circledR}$ DNA

157 Elution Accessory Kit (MoBio Laboratories), according to manufacturer's instructions.

158 Extract concentrations were measured with the Quant-iT RNA HS assay and the Quant-iT

159 dsDNA HS assay kits together with the Qubit fluorometer (Invitrogen, Lidingö, Sweden). The

160 RNA and DNA extraction yields ranged $2.5-122 \mathrm{ng} \mu \mathrm{l}^{-1}$ and $0.5-600 \mathrm{ng} \mu \mathrm{l}^{-1}$, respectively.

161 Two extractions from each sample were performed and combined after extraction. RNA

162 combined extractions were concentrated using the RNA Clean \& Concentrator ${ }^{\mathrm{TM}}-25$ (Zymo

163 Research, Taby, Sweden), in accordance with the manufacturer's instructions. DNA was

164 concentrated by the use of a Vacufuge ${ }^{\circledR}$ vacuum concentrator 5301 (Eppendorf, Horsholm,

165 Denmark). DNA residues were removed from the concentrated RNA extracts by digestion

166 using 2U TURBO DNase (Ambion-Life Technologies, Stockholm, Sweden) for $1 \mathrm{~h}$ at $37^{\circ} \mathrm{C}$

167 and according to manufacturer's instructions. Reverse transcription was performed adding 2

$168 \mu 1$ of DNAse-treated RNA to $17 \mu 1$ reaction mixture containing $1 X$ Expand Reverse

169 Transcriptase Buffer (Roche Diagnostics, Mannheim, Germany), 10mM of Dithiothreitol

170 (DTT) solution (Roche diagnostics), $5 \mathrm{mM}$ of dNTPs (New England BioLabs Inc., Glostrup,

171 Denmark) and $250 \mathrm{nM}$ of random hexamers (TAG Copenhagen A/S, Copenhagen, Denmark).

172 After 2 min incubation at $42^{\circ} \mathrm{C}$ in a DNA engine DYAD ${ }^{\mathrm{TM}}$ Peltier Thermal Cycler (MJ 
173

174

175

176

177

178

179

180

181

182

183

184

185

186

187

188

189

190

191

192

193

194

195

196

197

researchBio-Rad Laboratories, Hercules, CA), $1 \mu 1$ of Expand Reverse Transcriptase (Roche Diagnostics) was added to the mixture and incubated at $42^{\circ} \mathrm{C}$ for $40 \mathrm{~min}$ followed by $30 \mathrm{~min}$ at $50^{\circ} \mathrm{C}$ and $15 \mathrm{~min}$ at $72^{\circ} \mathrm{C}$. RNA template addition was in the range of $8-300 \mathrm{ng}$.

\section{Amplicon sequencing and sequences analysis}

PCR amplification of the bacterial and archaeal 16S rRNA and 16S rRNA gene V4 region fragment was performed using the primer pair 515F/806R (Caporaso et al. 2012) for all samples (Table S1). The primers used for amplicon sequencing of the 16S rRNA gene were selected following the Earth Microbiome Project recommendation

(http://www.earthmicrobiome.org/emp-standard-protocols/) representing the best choice at the initiation of the study. The primer $806 \mathrm{R}$ was previously modified to cover most available sequences in Genbank by Sundberg et al. (2013). More recently, these primers have been shown to be biased against Crenarcheota (Hugerth et al. 2014). Three $\mu$ l of template (cDNA or DNA) were added to a $20 \mu$ l-reaction mixture, consisting of $1 \mathrm{X}$ AccuPrime PCR Buffer II (Invitrogen), 0.2 U of AccuPrime Taq DNA Polymerase High Fidelity (Invitrogen) and 500 $\mathrm{nM}$ of each primer. The PCR assay was performed in a DNA engine DYAD ${ }^{\mathrm{TM}}$ Peltier Thermal Cycler (Bio-Rad Laboratories) with the following conditions: $94^{\circ} \mathrm{C}$ for $2 \mathrm{~min}$, followed by 35 cycles of $94^{\circ} \mathrm{C}$ for $20 \mathrm{~s}, 56^{\circ} \mathrm{C}$ for $30 \mathrm{~s}$ and $68^{\circ} \mathrm{C}$ for $40 \mathrm{~s}$, and a final extension at $68^{\circ} \mathrm{C}$ for $5 \mathrm{~min}$. PCR products were visualized on a $1 \%$ agarose gel. A second PCR using the same primers including adapters and indexes was performed under the same conditions as the previous PCR with the number of cycles reduced to 15. PCR amplicons were purified using Agencourt AMPure XP (Agencourt Bioscience Corporation, MA, USA) and concentration was measured using PicoGreen assay according to manufacturer's protocol (Invitrogen). To ensure equal representation of each sample, $50 \mathrm{ng}$ of each 16S rRNA and rRNA gene purified sample amplicons were pooled together before sequencing. Then the 
198 pooled mixture was purified and concentrated using the DNA Clean \& Concentrator ${ }^{\mathrm{TM}_{-} 5}$

199 (Zymo Research) followed by quantification with the Quant-iT dsDNA HS assay kit and the

200 Qubit fluorometer (Invitrogen). A paired-end 250-bp sequencing run was performed using the

201 Illumina MiSeq instrument according to the MiSeq ${ }^{\mathrm{TM}}$ Reagent Kit v2 Preparation Guide

202 (Illumina, Inc., San Diego, CA, USA).

203 Raw read data was processed using the ILLUMITAG pipeline (Sinclair et al. 2015). In

204 short, the read pairs from the 16S rRNA gene and 16S rRNA were demultiplexed and joined

205 using the PANDAseq software v2.4 (Masella et al. 2012). Next, assembled reads (from here

206 referred to as "reads") that did not have the correct primer sequences at the start and end of

207 their sequences were discarded. Reads were then filtered based on their PHRED scores.

208 Chimera removal and OTU (operational taxonomic unit) clustering at $1 \%$ sequence

209 dissimilarity was performed by pooling all reads from all samples (but separately for genomic

210 16S rRNA and 16S rRNA) together and applying the UPARSE algorithm v7.0.1001 (Edgar

211 2013). Here, any OTU containing less than two reads was discarded. Each OTU was

212 subsequently taxonomically classified by operating a similarity search against the SILVAmod

213 databases and employing the CREST assignment resource (Lanzen et al. 2012). Finally,

214 plastid and mitochondrial OTUs were removed.

215 We obtained a total of 4965761 sequence reads (including both, the 16S rRNA and 16S

216 rRNA gene), from which 4811127 sequences belonged to the domain Bacteria and 15444 to

217 the domain Archaea. Bacterial and archaeal sequences were analysed together as the

218 combined prokaryote community. Prior to estimating alpha diversity, to minimize the impact

219 of varying sequencing depth among the samples, the reads were rarefied to 5315 and 5455

220 sequences per sample for RNA and DNA, respectively. Three RNA and 2 DNA samples were

221 excluded due to low number of sequences (Table S1). Prokaryote richness and evenness

222 (alpha diversity) were estimated using the Chao1 and Pileou's indices, where a Pielou index 
of 1 represents absolute evenness. Prior to beta-diversity analyses and to avoid excluding samples, the number of reads for individual samples were rarefied to the minimum number of sequences observed per sample: 3331 and 3348 sequences for 16S rRNA and the 16S rRNA gene, respectively.

\section{Shotgun metagenome sequencing, assembly and annotation}

Shotgun sequencing was performed on samples from depths B $(11-15 \mathrm{~cm})$ and D $(19-23 \mathrm{~cm})$, (Table S1). Depth B corresponds to the level around which the mean growing season water table occurs, which is the depth horizon with the most metabolic activity. Depth D is below the growing season water table level fluctuations and, thus, continuously anoxic. 1ng of each DNA sample (from B and D depths) were used for tagmentation using the Nextera XT (Illumina, Inc., San Diego, CA, USA), according to manufacturer's instructions. Tagmented samples were purified using Agencourt AMPure XP (Agencourt Bioscience Corporation, MA, USA). Purified samples were visualized on a $1 \%$ agarose gel to ensure the libraries range was within 300-1000 bp. Libraries concentrations were measured with Quant-iT dsDNA HS assay and the Qubit fluorometer (Invitrogen). To ensure equal representation of each sample, $10 \mathrm{ng}$ of each sample library were pooled together before sequencing. A paired-end 150-bp sequencing run was performed using the Illumina Rapid Run on an Illumina HiSeq 2500 platform (Illumina, Denmark), according to manufacturer's instructions.

The obtained reads were quality-trimmed using Sickle (Joshi \& Fass 2011), and all samples were co-assembled with a range of k-mer values (from 31 to 101 with increments of 10) using Ray (Boisvert et al. 2012). The resulting assemblies were subsequently fragmented in silico into successive sequences of 2000 base pairs overlapping by $1900 \mathrm{bp}$ and were then merged using 454 Life Sciences's software Newbler (Roche, Basel, Switzerland) as previously described (Hugerth et al. 2015). The clean reads of all samples were mapped to the 
merged assembly using Bowtie (Langmead \& Salzberg 2012) after processing with SAMtools

249 (Li et al. 2009). Duplicates were removed using Picard (Broad Institute, Cambridge, MA,

250 USA). Finally, coverage was computed using BEDTools (Quinlan \& Hall 2010). PFAM

251 (protein families) annotation was performed using HMMer (Eddy 2011) using the PFAM A

252 database (Finn et al. 2014). For each sample, the coverage of all detected PFAMs was

253 normalized by dividing it by the mean coverage of a set single copy PFAMs (Rinke et al.

254 2013) in order to compile the coverage in a "per genome equivalent" form. PFAM tables

255 standardized to genome equivalents were resampled by removing PFAMs with smaller

256 genome equivalents than the highest minimum genome equivalent $\left(6.9 \times 10^{-4}\right)$ of sample

$257 \mathrm{NxGH}$.

\section{Statistical analyses}

260 The multifactorial experiment consists of three treatment factors at two levels $\left(2^{3}\right.$-design) with

261 field duplicates for each treatment. Thus, the statistical evaluation is based on $n=8$ for the

262 main factors $\mathrm{N}, \mathrm{S}$ and $\mathrm{GH}$ and $\mathrm{n}=4$ for the 2-way interaction treatments $(\mathrm{NxS}, \mathrm{NxGH}$ and

$263 \mathrm{SxGH})$ and $\mathrm{n}=2$ for the 3-way interaction $(\mathrm{NxSxGH})$, see Table $\mathrm{S} 2$ for the treatment effect

264 evaluation matrix. After 10 years of treatment, the addition of $\mathrm{N}$ had significantly reduced the

265 distance between the mire surface and the growing season average water table (Eriksson et al.

266 2010b). To account for this gradual change and the inherent variation among the plots, the

267 sampled depths were classified according to their positions relative to the average growing

268 seasonal water table level within each plot as given by (Eriksson et al. 2010a), (Table S3).

269 This resulted in three different depth horizons: an upper layer above the growing season mean

270 water table level, which will be the most oxic of the three (AWT), a layer around the growing

271 season mean water table level (WT) and a third layer below the growing season mean water

272 table level characterized by permanent anoxic conditions (BWT). 
ANOVA was applied to test for the effects of the treatments on the prokaryotic alpha-

274 diversity. Permutation analysis of variance (PERMANOVA) was applied to test the

275 hypothesis that the prokaryotic community composition and its functional potential differed

276 among the treatments. To assess whether the microbial composition turnover in the treatment

277 plots followed the same direction, ordination by non-metric multidimensional scaling was

278 used. In order to understand how the response of the microbial community was distributed

279 across the different phyla, we used the integrated occurrence of each phylum along the entire

280 peat profiles and calculated the average change in their relative abundance derived from the

281 16S rRNA for the high treatment levels in relation to their corresponding low levels. The

282 phyla were sorted according to their relative abundance in the combined 16S rRNA dataset

283 and are presented with either positive or negative responses to the treatments. In this context,

284 it should be noted that changes at the phylum level might only be a rough representation of

285 changes in the functional capacity of the communities. To assess individual metabolic traits in

286 the different treatments, we applied generalized linear models (GLMs) on genome equivalent

287 standardized PFAMs across the different treatments. We focused on PFAMs predicting key

288 enzymes involved in the anaerobic degradation of soil organic matter, as well as

289 methanotrophy (Table S4). The resulting differentially abundant categories (taxa or functional

290 subsystems) among samples were identified based on $\mathrm{p}<0.05$ and false discovery rate was

291 estimated (Benjamini \& Hochberg 1995). A distance-based redundancy analysis (db-RDA)

292 was applied to explore possible multiple linear correlations between the microbial community

293 composition and the vegetation composition previously reported (Eriksson et al. 2010b).

294 Correspondence between the different data sets was investigated using procrustes

295 superimposition combined with a randomisation test (Peres-Neto \& Jackson 2001). Bray-

296 Curtis distance was used when a distance matrix was required applying 999 permutations. The

297 statistic discrimination throughout the analyses was at a significance level of 0.05. 


\section{Nucleotide sequence accession numbers}

300 The sequence data generated in this study was deposited to the NCBI Sequence Read Archive 301 and is accessible through accession number PRJEB14741.

\section{Results}

\section{Microbial community composition}

High throughput sequencing data was used to follow prokaryotic community composition and metabolic traits responding to the perturbations in the factorially designed experiment. High concordance was observed between the 16S rRNA gene and 16S rRNA-derived community compositions, as determined by procrustes superimposition $(\mathrm{p}=0.001, \mathrm{R}=0.9$; Table $\mathrm{S} 5)$. Comparisons of treatments revealed that the three main factors (nitrogen $(\mathrm{N})$, sulfate $(\mathrm{S})$ and warming (GH)) significantly affected the prokaryote community compositions (i.e. the betadiversity; Table 1). In all cases, enhanced inorganic $\mathrm{N}$ deposition (high level) significantly affected the community composition at all depth horizons, contributed the most to the explained variance (Table 1), and showed the highest degree in dissimilarity compared to the ambient N (low level) (Fig. 1). In contrast to beta-diversity describing compositional changes (as determined by Bray-Curtis distances), alpha-diversity assessed as prokaryotic richness and evenness estimates, revealed only few significant responses to the perturbations (Table 1). Richness increased with the warming effect, while evenness overall decreased as a result of all the perturbations (Fig. S1).

The combined perturbations (i.e. high levels of $\mathrm{NxS}, \mathrm{NxGH}, \mathrm{SxGH}$ and $\mathrm{NxSxGH}$ ) caused significant interactive effects that shifted the prokaryotic community (i.e. the beta-diversity: Table 1 and Fig. 1). For example, the 16S rRNA gene-derived prokaryotic community (betadiversity) response to warming increased with enhanced $\mathrm{N}$ deposition in the two upper 
horizons, while enhanced S deposition significantly increased the warming effect below the water table. Such synergistic effects were also observed when combining $\mathrm{N}$ and S deposition. While treatment interactions appeared to be additive as based on the observation that the dissimilarity among communities increased when applying multiple perturbations, their directionality were not consistent (Fig. 1 and Fig. S2). This implies that communities experiencing impacts from multiple perturbations do not merely change in a linear fashion based on combinations of individual perturbations, but are emerging in response to the establishment of unique communities for a particular combination of effectors. For example, enhanced $\mathrm{N}$ deposition combined with another perturbation ( $\mathrm{NxS}, \mathrm{NxGH}$ and $\mathrm{NxSxGH}$ ) tended to cause greater community changes compared to the single perturbations at the two upper layers (Fig. 1a and 1b). Below the growing season mean water table (BWT) horizon, the amplitudes of the community composition responses in comparison to the control were similar for all perturbations (Fig. 1c).

There was concordance between beta diversity of the plant vegetation, derived from Wiedermann et al. (2007), and the peat prokaryote community at all three depth horizons, as revealed by procrustes superimposition $(\mathrm{p}=0.001, \mathrm{R}=0.4-0.7$; Table $\mathrm{S} 5)$. In addition, $\mathrm{db}-$ RDA analyses revealed that the prokaryotic composition in the treatments receiving $\mathrm{NH}_{4} \mathrm{NO}_{3}$ (high N) were positively correlated with the relative abundance of the dominant vascular plants (E. vaginatum, A. polifolia and V. oxycoccus) and negatively correlated with total Sphagnum and S. balticum coverage (Fig. S3).

Bacterial and archaeal 16S rRNA gene sequences and expressed 16S rRNA sequences were classified into 31 and 33 phyla, respectively. The main phyla were Verrucomicrobia and Acidobacteria accounting respectively for $39 \%$ and $26 \%$ of the reads in the $16 \mathrm{~S}$ rRNA genederived community, while Acidobacteria accounted for $36 \%$ and Proteobacteria for $23 \%$ of the reads in the $16 \mathrm{~S}$ rRNA-derived community. The abundance of the different phyla was 
clearly and differentially affected by the perturbations (Fig. 2). For example, the phyla

349 Acidobacteria, Firmicutes, and Armatimonadetes decreased in relative abundance in response

350 to all the treatments, while Chlorobi, Euryarchaeota, Fibrocateretes, and Tenericutes showed

351 the opposite response. Verrucomicrobia and Actionabacteria increased in response to the main

$352 \mathrm{~N}$ effect and decreased in the other treatments, while candidate phylum BD1-5 had the

353 opposite response. Cyanobacteria and Fusobacteria, increased in response to the main

354 warming effect while for all the other treatments decreased and disappeared, respectively.

355 Dictyoglomi increased with N, GH and NxGH while disappeared with all the other

356 treatments. Thaumarchaetoa and candidate division TM7 disappeared with warming while

357 increased with $\mathrm{N}, \mathrm{S}$ and NxS perturbations.

\section{Microbial metabolic traits}

360 In addition to responses in the composition of operational taxonomic units and taxonomic

361 groups at the phylum level, we assessed the treatment responses with regards to genome-

362 encoded metabolic traits from shotgun metagenomic data. In total, protein-coding genes

363 matching 4957 protein families (PFAMs) were found from the 31 metagenomes. Overall

364 responses in the functional potential as determined by estimating Bray-Curtis distances

365 revealed that only enhanced $\mathrm{N}$ deposition (high $-\mathrm{N}$ ) caused a significant shift in functional

366 attributes, and this was only observed below the water table (Table 1). There was also a

367 significant interactive effect when warming and increased S deposition perturbations were

368 combined (Table 1).

369 Moreover, we specifically searched for marker genes related to key steps in the anaerobic

370 degradation of organic matter (e.g. nitrate- and sulfate reduction, hydrolysis, fermentation,

371 methanogenesis) and aerobic methane and ammonia oxidation (Table S4). From 1057

372 possible responses at each depth horizon, merely 24 significant responses $(p<0.05$; FDR of 
0.30) could be extracted from above the growing season mean water table (AWT), while the corresponding number in samples from below the growing season mean water table (BWT) was 30. At the AWT horizon, a few genes encoding for key steps in processes such as methanogenesis, sulfate reduction, nitrate reduction, sulfur oxidation, nitrogen fixation, syntrophy and hydrolysis, responded significantly to the experimental treatments (Fig. 3a). The majority of significant responses were connected to the 2-way interactive terms (NxS, $\mathrm{NxGH}$ and $\mathrm{SxGH})$. Marker genes for methanogenesis significantly decreased in response to the main effects (N, S and GH), with amplification effects connected to the $\mathrm{NxSxGH}$ interaction, while they increased in response to the 2-way interactive terms. Genes encoding for proteins involved in dissimilatory sulfate reduction increased under enhanced $\mathrm{S}$ deposition, with amplification effects under the three-way perturbation and a decrease in the response when combined with warming or $\mathrm{N}$.

At the BWT horizon, only a few genes encoding for methanogenesis, sulfate reduction, nitrate reduction, sulfur oxidation, syntrophy, and hydrolases responded significantly to the treatments. At this horizon the majority of the responses were connected to warming and enhanced $\mathrm{S}$ deposition, both resulting in a decrease of the different metabolic potentials, except for sulfate reduction that increased with the elevated S deposition (Fig. 3b). However, the few significant effects of the 2- and 3-way interactions with S or GH seemed to counteract these responses, resulting in an increase of the respective metabolic traits. For example, marker genes for methanogenesis, as observed for the AWT horizon, significantly decreased in response to the individual $\mathrm{S}$ and $\mathrm{GH}$ effects but increased in response to the $\mathrm{NxS}$ and NxSxGH perturbations. Genes encoding for hydrolases were the most affected among the studied metabolic traits, and mainly decreased with warming and enhanced S deposition as well as with simultaneous increase in $\mathrm{N}$ and $\mathrm{S}$ depositions. 


\section{Co-variations between ecosystem functions and genetics in the light of perturbations}

399 Taxonomic composition and genome-encoded traits were tightly coupled $(\mathrm{p}=0.001, \mathrm{R}=$ and the taxonomic composition data at $16 \mathrm{~S}$ rRNA level were strongly related to each other across the different treatments and depth horizons (Table 2). However, genome-encoded

403 functional traits as assessed from shotgun metagenomic data, including marker genes for methanogenesis and methanotrophy, did not correspond with measured function (i.e. methane production and oxidation; data no shown).

\section{Discussion}

The long field experiment at the Degerö Stormyr peatland was established to investigate the

effects of increased nitrogen (N) and sulfur (S) deposition as well as warming on methane and

411 interactive long-term effects after 18 years of multiple perturbations on prokaryotic taxonomic

412 diversity and genome-encoded traits, as well as their relationship with ecosystem-scale processes of interest (i.e. methane cycling, organic matter degradation and plant composition).

414 The microbial taxonomic composition largely corresponds with results from previous studies

415 of peatlands (Lin et al. 2012, Serkebaeva et al. 2013, Tveit et al. 2013). Thus, the proportion

416 of archaeal sequences at $0.3 \%$ of total prokaryotic sequences was in the range of what has

417 previously been observed for peat ecosystems (Tveit et al. 2013 and references therein). We

418 also show that where vascular plants (E. vaginatum, A. polifolia and V. oxycoccus) replaced

419 Sphagnum under N amendments (Wiedermann et al. 2007, Eriksson et al. 2010b), also

420 prokaryotic communities shifted in composition in response to $\mathrm{N}$ additions. The concordance

421 between beta-diversity of the plant vegetation composition derived from Wiedermann et al.

422 (2007) and the composition of the peat prokaryote community, confirms the tight coupling 
between vegetation and microbes in the peat biome. The enrichments of roots at $10-15 \mathrm{~cm}$ into the peat vertical profile (Olid et al. 2017) likely play an essential role for this nutrient poor bogs. Since both phyla contain anaerobic carbohydrate polymer degrading representatives, these phyla may replace one another (cf. Schmidt et al. 2015) as result of changes in the type of carbohydrates supplied by the different plant communities forming the peat. The decrease in Cyanobacteria may reflect the decrease in Sphagnum abundance. to perform dinitrogen fixation (cf. Granhall \& Selander 1973, Granhall \& von Hofsten 1976,

439 Berg et al. 2013). In addition to the taxonomic composition, also the genome-derived 440 functional potential (PFAMs) was related to the composition of the vegetation. As such, our 441 results fit the framework developed in studies of other soils subject to long-term $\mathrm{N}$ addition 442 experiments, both with regards to microbial community composition and functional potential

443 (Ramirez et al. 2010, Fierer et al. 2012, Leff et al. 2015, Zhou et al. 2015, Boot et al. 2016, 444 Zeng et al. 2016), including grasslands, agricultural fields, agricultural black soils, and 445 subalpine forests. For these systems, there is a consistent view that the shifts in microbial 446 community composition and their metabolic functionality is due to the soil-plant-microbe 447 interactions driven by $\mathrm{N}$ loading. 
The significant relationships between prokaryotic community composition and methane oxidation and production, further emphasize the role of plant-prokaryotic interactions in regulating methane emissions. This is corroborated by the fact that all $\mathrm{N}$ amended to the plots is retained in the organic fraction of the peat (Eriksson 2010). However, responses in the overall set of genes, as well as the specific marker genes for methanogenesis and methanotrophy, did not match the patterns of observed methane production and consumption rates previously reported (Eriksson et al. 2010a). There are multiple possible explanations for the lack of correspondence, including an actual decoupling between gene abundance and their expression (Roling 2007, Freitag \& Prosser 2009) or a high variability of the genomic content between individual samples. Also, temporal variation could play a role, as methane processing rates and genetic data were obtained during different years and locations within the treatment 459 plots.

460 Similar to the elevated $\mathrm{N}$ deposition, also warming led to changes in prokaryotic community composition, supporting earlier findings of decreased methane production and emission rates while methane oxidation was unaffected (Eriksson et al. 2010a, Eriksson et al. 2010b). Thus, the relative abundance of genes involved in methanogenesis decreased in

464 response to warming, while other metabolic traits such as methanotrophy were largely unaffected. The observed decrease in the methanogenic potential may be explained by lower 466 input of easily degradable organic matter to the anoxic zone due to oxygen-exposure in the 467 upper layers with higher temperature (Nilsson \& Öquist 2009). Thus, the organic matter will 468 be more recalcitrant when it is transferred into the permanent anoxic layer. In favour of this 469 explanation, there was a decrease in the hydrolytic potential below the water table level 470 pinpointing to a lower degradability of the biopolymers at these strata.

471 The enhanced S deposition affected the microbial taxonomic composition at the water table 472 and the anoxic horizons. Although S amendment in the field did not have any effects on 
methane emissions, laboratory incubations of the methane producing-layers have shown a decrease in methane production by $55 \%$ in response to $\mathrm{S}$ amendments (Eriksson et al. 2010a, Eriksson et al. 2010b). This observation is supported by our results that the relative abundance of genes involved in methanogenesis were lower in the S-supplied plots. Below the water table, the observed decrease in hydrolytic and syntrophic potential combined with an increase of sulfate reduction potential, imply that organic matter degradation resulted in lower amounts of metabolic fermentation intermediates and $\mathrm{H}_{2}$ available for methanogenesis.

Above the water table, the sulfate reduction potential increased concomitantly with the observed decrease in methanogenic potential as expected from the thermodynamic constraints (Abram \& Nedwell 1978, Kristjansson et al. 1982). Some of the sulfide generated in this process is likely emitted to the atmosphere at the prevailing low $\mathrm{pH}$, while experimentally added S over the years has contributed to a 50\% larger S-pool under ambient climate and to a $\sim 15 \%$ larger S-pool when combined with the greenhouse treatment (Granberg et al. 2001, Åkerblom et al. 2013). A re-oxidation of this residual S-pool would result in a continuous supply of oxidized sulfur compounds that would sustain sulfate reduction in these treatments. The increase of the photosynthetic sulfur oxidizers, here represented by the phylum Chlorobi, in response to essentially all perturbations and in particular the S amendments, supports the presence of an internal sulfur cycle (Pester et al. 2010, Pester et al. 2012). Such a sulfur cycle is suggested to be involved in the regulation of the ratio between carbon dioxide to methane formation in peatlands (Pester et al. 2010, Pester et al. 2012).

The nitrogen applied has been shown to be completely retained for the duration of the experiment in the form of nitrogenous organic matter (Eriksson 2010). Because of this, the amendment of $\mathrm{N}$ to these highly nitrogen-limited systems is not expected to enhance the occurrence of ammonia oxidation, dissimilatory nitrate reduction to ammonia or denitrification. This is supported by the lack of any significant response of genes encoding for 
these processes in the $\mathrm{N}$-amended plots. However, the 16S RNA analysis revealed that phyla hosting archaeal nitrifiers were present and increased in the plots with $\mathrm{N}$ addition. Especially, the positive response by groups within the Thaumarchaeota that have been shown to oxidize

501 ammonia at very low levels, would potentially supply nitrite in the high-level $\mathrm{N}$ treatments.

502 However, any nitrite formed would likely be immediately reduced by means of

503 denitrification, anaerobic ammonium oxidation or assimilative or dissimilative reduction to 504 ammonia.

\section{Conclusions}

507 Experimental long-term treatments mimicking anthropogenic perturbations altered the 508 microbial communities at the taxonomic level and to some extent redistribute genes encoding 509 microbial metabolic profiles including changes in ecosystem-relevant traits, such as sulfate 510 reduction and methanogenesis, partly coinciding with expressed overall ecosystem functions.

511 The results from the 18-years field manipulation experiment emphasizes that interactive 512 effects of multiple anthropogenic perturbations on ecosystem services lead to idiosyncratic 513 and hard to predict disturbance-responses in natural microbial communities when studying 514 each perturbation in isolation. The observed additive effects of the treatments on community 515 composition and function emphasize the need for studying interactions among multiple 516 anthropogenic perturbations to understand ecosystem responses to climate change.

\section{Acknowledgements}

519 We thank Lucas Sinclair for bioinformatics support and the Uppsala Multidisciplinary Center 520 for Advanced Computational Science (UPPMAX) for the computational and storage 521 resources under projects b2014318. The project was mainly funded by the Swedish Research 522 Council (contract no: 621-2011-4901) and additional research grants from the Swedish 
Research Council Formas to MN and SB and from the Swedish Research Council to AE, BS,

MN and SB further supported the study. We are thankful to FEMS for the research fellowship

(FRF 2014-1) award (MM).

\section{References}

528

529

530

531

532

533

534

535

536

537

538

539

540

541

542

543

544

545

546

547

548

549

550

551

552

553

554

555

556

557

558

559

560

561

562

563

564

565

566

567
Abram JW \& Nedwell DB (1978) Inhibitionof Methanogenesisby Sulfphate Reducing Bacteria Competing for Transferred Hydrogen. Archives of Microbiology, 117: 89-92.

Åkerblom S, Bishop K, Björn E, Lambertsson L, Eriksson T \& Nilsson M (2013) Significant interaction effects from sulfate deposition and climate on sulfur concentrations constitute major controls on methylmercury production in peatlands. Geochimica et Cosmochimica Acta 1-11.

Andresen LC, Dungait JA, Bol R, Selsted MB, Ambus P \& Michelsen A (2014) Bacteria and fungi respond differently to multifactorial climate change in a temperate heathland, traced with 13C-glycine and FACE CO2. PloS One 9: e85070.

Benjamini Y \& Hochberg Y (1995) Controlling the false discovery rate: a practical and powerful approach to multiple testing. Journal of the Royal Statistical Society Series B: 289-300.

Berg A, Danielsson Å \& Svensson BH (2013) Transfer of fixed-N from N2-fixing cyanobacteria associated with the moss Sphagnum riparium results in enhanced growth of the moss. Plant and Soil: 271-278.

Boisvert S, Raymond F, Godzaridis E, Laviolette F \& Corbeil J (2012) Ray Meta: scalable de novo metagenome assembly and profiling. Genome Biology 13: R122.

Boot CM, Hall EK, Denef K \& Baron JS (2016) Long-term reactive nitrogen loading alters soil carbon and microbial community properties in a subalpine forest ecosystem. Soil Biology and Biochemistry 92: 211-220.

Bragazza L, Bardgett RD, Mitchell EA \& Buttler A (2015) Linking soil microbial communities to vascular plant abundance along a climate gradient. New Phytologist 205: 1175-1182.

Bridgham SD, Pastor J, Janssens JA, Chapin C \& Malterer TJ (1996) Multiple limiting gradients in peatlands: a call for a new paradigm. Wetlands 16: 45-65.

Caporaso JG, Lauber CL, Walters WA, et al. (2012) Ultra-high-throughput microbial community analysis on the Illumina HiSeq and MiSeq platforms. ISME J 6: 1621-1624.

Castro HF, Classen AT, Austin EE, Norby RJ \& Schadt CW (2010) Soil microbial community responses to multiple experimental climate change drivers. Applied and Environmental Microbiology 76: 999-1007.

Contosta AR, Frey SD \& Cooper AB (2015) Soil microbial communities vary as much over time as with chronic warming and nitrogen additions. Soil Biolology and Biochemistry 88: 19-24.

Damman A (1988) Regulation of nitrogen removal and retention in Sphagnum bogs and other peatlands. Oikos 51: 291-305.

Eddy SR (2011) Accelerated Profile HMM Searches. PLoS Computational Biology 7: e1002195.

Edgar RC (2013) UPARSE: highly accurate OTU sequences from microbial amplicon reads. Nature Methods 10: 966-988. 
Eppinga MB, Rietkerk M, Belyea LB, Nilsson MB, De Ruiter PC \& Martin JW (2010) Resource contrast in patterned peatlands increases along a climatic gradient. Ecology 91: 2344-2355.

Eriksson T (2010) Boreal Mire Carbon Exchange. Dissertation. Serie: Acta Universitatis agriculturae Sueciae, 1652-6880; 2010:62

Eriksson T, Öquist MG \& Nilsson MB (2010a) Production and oxidation of methane in a boreal mire after a decade of increased temperature and nitrogen and sulfur deposition. Global Change Biology 16: 2130-2144.

Eriksson T, Öquist MG \& Nilsson MB (2010b) Effects of decadal deposition of nitrogen and sulfur, and increased temperature, on methane emissions from a boreal peatland. Journal of Geophysical Research 115: 1 -13.

Fierer N, Lauber CL, Ramirez KS, Zaneveld J, Bradford MA \& Knight R (2012) Comparative metagenomic, phylogenetic and physiological analyses of soil microbial communities across nitrogen gradients. ISME J 6: 1007-1017.

Finn RD, Bateman A, Clements J, et al. (2014) Pfam: the protein families database. Nucleic Acids Research 42: D222-230.

Freitag TE \& Prosser JI (2009) Correlation of methane production and functional gene transcriptional activity in a peat soil. Applied and Environmental Microbiology 75: 6679-6687.

Galloway JN, Dentener FJ, D.G. C, et al. (2004) Nitrogen cycles: past, present, and future. Biogeochemistry 70: 153-226.

Gauci V, Matthews E, Dise N, Walter B, Koch D, Granberg G \& Vile M (2004) Sulfur pollution suppression of the wetland methane source in the 20th and 21 st centuries. Proceedings of the National Academy of Sciences of the United States of America 101: 12583-12587.

Gorham E (1991) Northern peatlands: role in the carbon cycle and probable responses to climatic warming. Ecological Applications 1: 182-195.

Granberg G, Sundh I, Svensson BH \& Nilsson M (2001) Effects of temperature, and nitrogen and sulfur deposition, on methane emission from a boreal mire. Ecology 82: 1982-1998.

Granhall U \& Selander H (1973) Nitrogen fixation in a subarctic mire. Oikos 24: 8-15.

Granhall U \& von Hofsten A (1976) Nitrogenase activity in relation to intracellular organisms in Sphagnum Mosses. Physiologia plantarum 36: 88-94.

Hugerth LW, Larsson J, Alneberg J, Lindh MV, Legrand C, Pinhassi J \& Andersson AF (2015) Metagenome-assembled genomes uncover a global brackish microbiome. Genome Biology 16: 279.

Hugerth LW, Muller EE, Hu YO, Lebrun LA, Roume H, Lundin D, Wilmes P \& Andersson AF (2014) Systematic design of 18S rRNA gene primers for determining eukaryotic diversity in microbial consortia. PloS One 9: e95567.

Joshi NA \& Fass JN (2011) Sickle: A sliding-window, adaptive, quality-based trimming tool for FastQ files (Version 1.33) [Software]. Available at https://githubcom/najoshi/sickle.

Juottonen H, Eiler A, Biasi C, Tuittila ES, Yrjala K \& Fritze H (2017) Distinct Anaerobic Bacterial Consumers of Cellobiose-Derived Carbon in Boreal Fens with Different $\mathrm{CO} 2 / \mathrm{CH} 4$ Production Ratios. Applied and Environmental Microbiology 83: e0253302516.

Kristjansson JK, Schonheit P \& Thauer RK (1982) Different Ks values for hydrogen of methanogenic bacteria and sulfate reducing bacteria - an explanation for the apparent inhibition of methanogenesis by sulfate. Archives of Microbiology, 131: 278-282. Langmead B \& Salzberg SL (2012) Fast gapped-read alignment with Bowtie 2. Nature Methods 9: 357-359. 
Lanzen A, Jorgensen SL, Huson DH, Gorfer M, Grindhaug SH, Jonassen I, Ovreas L \& Urich T (2012) CREST--classification resources for environmental sequence tags. PloS One 7: e49334.

Lawton JH \& Brown VK (1993) Redundancy in ecosystems. In: (Schulze ED \& Mooney HA, ed) Biodiversity and Ecosystem Function, Springer-Verlag Berlin, Germany, pp. 255270.

Leff JW, Jones SE, Prober SM, et al. (2015) Consistent responses of soil microbial communities to elevated nutrient inputs in grasslands across the globe. Proceedings of the National Academy of Sciences of the United States of America 112: 10967-10972.

Li H, Handsaker B, Wysoker A, Fennell T, Ruan J, Homer N, Marth G, Abecasis G, Durbin R \& Genome Project Data Processing S (2009) The Sequence Alignment/Map format and SAMtools. Bioinformatics 25: 2078-2079.

Li Q, Bai H, Liang W, Xia J, Wan S \& van der Putten WH (2013) Nitrogen addition and warming independently influence the belowground micro-food web in a temperate steppe. PloS One 8: e60441.

Limpens J, Granath G, Gunnarsson U, et al. (2011) Climatic modifiers of the response to nitrogen deposition in peat-forming Sphagnum mosses: a meta-analysis. New Phytologist 191: 496-507.

Lin X, Green S, Tfaily MM, Prakash O, Konstantinidis KT, Corbett JE, Chanton JP, Cooper WT \& Kostka JE (2012) Microbial community structure and activity linked to contrasting biogeochemical gradients in bog and fen environments of the Glacial Lake Agassiz Peatland. Applied and Environmental Microbiology 78: 7023-7031.

Martiny JB, Jones SE, Lennon JT \& Martiny AC (2015) Microbiomes in light of traits: A phylogenetic perspective. Science 350: aac9323.

Masella AP, Bartram AK, Truszkowski JM, Brown DG \& Neufeld JD (2012) PANDAseq: PAired-eND Assembler for Illumina sequences. BMC Bioinformatics 13.

McCalley CK, Woodcroft BJ, Hodgkins SB, et al. (2014) Methane dynamics regulated by microbial community response to permafrost thaw. Nature 514: 478-481.

Nielsen UN, Ayres E, Wall DH \& Bardgett RD (2011) Soil biodiversity and carbon cycling: a review and synthesis of studies examining diversity-function relationships. European Journal of Soil Science 62: 105-116.

Nilsson M \& Öquist M (2009) Partitioning Litter mass Loss Into Carbon Dioxide and Methane in Peatland Ecosystems. Geophysical Monograph 184: 131-144.

Nilsson M, Sagerfors J, Buffam I, Laudon H, Eriksson T, Grelle A, Klemedtsson L, Weslien PER \& Lindroth A (2008) Contemporary carbon accumulation in a boreal oligotrophic minerogenic mire - a significant sink after accounting for all C-fluxes. Global Change Biology 14: 2317-2332.

Olid C, Bindler R, Nilsson MB, Eriksson T \& Klaminder J (2017) Effects of warming and increased nitrogen and sulfur deposition on boreal mire geochemistry. Applied Geochemistry 78: 149-157.

Peichl M, Sonnentag O \& Nilsson MB (2014) Bringing color into the picture: using digital repeat photography to investigate phenology controls of the carbon dioxide exchange in a boreal mire. Ecosystems 18: 115-131.

Peres-Neto P \& Jackson D (2001) How well do multivariate data sets match? The advantages of a Procrustean superimposition approach over the Mantel test. Oecologia 129: 169178.

Pester M, Bittner N, Deevong P, Wagner M \& Loy A (2010) A 'rare biosphere' microorganism contributes to sulfate reduction in a peatland. ISME J 4: 1591-1602. 
Pester M, Knorr KH, Friedrich MW, Wagner M \& Loy A (2012) Sulfate-reducing microorganisms in wetlands - fameless actors in carbon cycling and climate change. Front Microbiol 3: 72.

Phoenix GK, Emmett BA, Britton AJ, et al. (2012) Impacts of atmospheric nitrogen deposition: responses of multiple plant and soil parameters across contrasting ecosystems in long-term field experiments. Global Change Biology 18: 1197-1215.

Quinlan AR \& Hall IM (2010) BEDTools: a flexible suite of utilities for comparing genomic features. Bioinformatics 26: 841-842.

Ramirez KS, Lauber CL, Knight R, Bradford MA \& Fierer N (2010) Consistent effects of nitrogen fertilization on soil bacterial communities in contrasting systems. Ecology 91: 3463-3470.

Rinke C, Schwientek P, Sczyrba A, et al. (2013) Insights into the phylogeny and coding potential of microbial dark matter. Nature 499: 431-437.

Rinnan R, Michelsen A, Bååth E \& Jonasson S (2007) Fifteen years of climate change manipulations alter soil microbial communities in a subarctic heath ecosystem. Global Change Biology 13: 28-39.

Roling WF (2007) Do microbial numbers count? Quantifying the regulation of biogeochemical fluxes by population size and cellular activity. FEMS Microbiology Ecology 62: 202-210.

Roulet NT, Lafleur PM, Richard PJH, Moore TR, Humphreys ER \& Bubier J (2007) Contemporary carbon balance and late Holocene carbon accumulation in a northern peatland. Global Change Biology 13: 397-411.

Schmidt O, Horn MA, Kolb S \& Drake HL (2015) Temperature impacts differentially on the methanogenic food web of cellulose-supplemented peatland soil. Environ Microbiol 17: 720-734.

Serkebaeva YM, Kim Y, Liesack W \& Dedysh SN (2013) Pyrosequencing-based assessment of the bacteria diversity in surface and subsurface peat layers of a northern wetland, with focus on poorly studied phyla and candidate divisions. PloS One 8: e63994.

Shen R-C, Xu M, Chi Y-G, Yu S \& Wan S-Q (2014) Soil Microbial Responses to Experimental Warming and Nitrogen Addition in a Temperate Steppe of Northern China. Pedosphere 24: 427-436.

Sinclair L, Ahmed O, Bertilsson S \& Eiler A (2015) Microbial community composition and diversity via $16 \mathrm{~S}$ rRNA gene amplicons: evaluating the Illumina platform. PloS One 10: e0116955.

Sundberg C, Al-Soud WA, Larsson M, Alm E, Shakeri Yekta S, Svensson BH, Sorensen SJ \& Karlsson A (2013) 454-Pyrosequencing Analyses of Bacterial And Archaeal Richness In 21 Full-Scale Biogas Digesters. FEMS Microbiology Ecology 85: 612-626.

Tully BJ, Wheat CG, Glazer BT \& Huber JA (2018) A dynamic microbial community with high functional redundancy inhabits the cold, oxic subseafloor aquifer. ISME J 12: 1-16. Turetsky MR, Kotowska A, Bubier J, et al. (2014) A synthesis of methane emissions from 71 northern, temperate, and subtropical wetlands. Global Change Biology 20: 2183-2197.

Turunen J, Tomppo E, Tolonen K \& Reinikainen A (2002) Estimating carbon accumulation rates of undrained mires in Finland-application to boreal and subarctic regions. The Holocene 12: 69-80.

Tveit A, Schwacke R, Svenning MM \& Urich T (2013) Organic carbon transformations in high-Arctic peat soils: key functions and microorganisms. ISME J 7: 299-311.

Wang M \& Moore TR (2014) Carbon, nitrogen, phosphorus, and potassium stoichiometry in an ombrotrophic peatland reflects plant functional type. Ecosystems 17: 673-684.

Wiedermann MN, Nordin A, Gunnarsson U, Nilsson MB \& Ericsson L (2007) Global change shifts vegetation and plant-parasite interactions in a boreal mire. Ecology 88: 454-464. 
Yu ZC (2012) Northern peatland carbon stocks and dynamics: a review. Biogeosciences 9: 4071-4085. directly affects soil bacterial diversity and indirectly affects bacterial community composition. Soil Biology and Biochemistry 92: 41-49.

Zhou J, Guan D, Zhou B, et al. (2015) Influence of 34-years of fertilization on bacterial communities in an intensively cultivated black soil in northeast China. Soil Biology and Biochemistry 90: 42-51. 
Table 1 Statistical tests for the 16S rRNA gene sequences, 16S rRNA sequences and protein families derived from the metagenome (PFAM) in relation to the treatments and the standardized depths: above the growing season water table (AWT), around the growing season mean water table (WT), and below the growing season mean water table (BWT). PFAMs were only analysed at the AWT and BWT depths. N, S and GH refer to the main treatment effects of nitrogen, sulfur and greenhouse, and $\mathrm{NxS}, \mathrm{NxGH}$ and $\mathrm{SxGH}$ refer to their two-way interactions, while $\mathrm{NxSxGH}$ represents the three-way combination. Only R2-values from the significant results of a permutational multivariate analysis of variance (PERMANOVA) are presented. Similar for the alpha-diversity, only Pielou (evenness index) and Chao (richness index) are represented from the significant results of an ANOVA.

\begin{tabular}{|c|c|c|c|c|c|}
\hline \multirow{2}{*}{ Data } & & \multirow{2}{*}{ Effect } & \multicolumn{3}{|c|}{ Standardized depth } \\
\hline & & & AWT & WT & BWT \\
\hline \multirow[t]{14}{*}{ Beta-diversity } & 16S rRNA & $\mathrm{N}$ & $0.25^{* * *}$ & $0.18^{* *}$ & $0.08^{* * *}$ \\
\hline & gene & $\mathrm{S}$ & ns & $0.06^{*}$ & $0.03^{*}$ \\
\hline & & $\mathrm{GH}$ & $0.07^{*}$ & $0.09^{* *}$ & $0.05^{* * *}$ \\
\hline & & $\mathrm{NxS}$ & ns & $0.05^{*}$ & ns \\
\hline & & $\mathrm{NxGH}$ & $0.06^{*}$ & $0.05^{*}$ & ns \\
\hline & & $\mathrm{SxGH}$ & ns & ns & $0.03^{*}$ \\
\hline & & $\mathrm{NxSxGH}$ & $0.05^{*}$ & ns & $0.03 *$ \\
\hline & 16S rRNA & $\mathrm{N}$ & $0.15^{* *}$ & $0.12^{*}$ & $0.09 * * *$ \\
\hline & & $S$ & ns & $0.07^{*}$ & $0.04^{* *}$ \\
\hline & & GH & ns & $0.06^{*}$ & $0.05^{* *}$ \\
\hline & & $\mathrm{NxS}$ & ns & $0.05^{*}$ & $0.03^{*}$ \\
\hline & & $\mathrm{NxGH}$ & ns & ns & ns \\
\hline & & $\mathrm{SxGH}$ & ns & ns & ns \\
\hline & & $\mathrm{NxSxGH}$ & ns & ns & ns \\
\hline \multirow{7}{*}{$\begin{array}{l}\text { Functional } \\
\text { potential }\end{array}$} & PFAM & $\mathrm{N}$ & ns & & $0.14^{*}$ \\
\hline & & $\mathrm{S}$ & ns & & ns \\
\hline & & GH & ns & & ns \\
\hline & & $\mathrm{NxS}$ & ns & & ns \\
\hline & & $\mathrm{NxGH}$ & ns & & ns \\
\hline & & $\mathrm{SxGH}$ & ns & & $0.13^{*}$ \\
\hline & & $\mathrm{NxSxGH}$ & ns & & ns \\
\hline \multirow{14}{*}{$\begin{array}{l}\text { Alpha- } \\
\text { diversity }\end{array}$} & 16S rRNA & $\mathrm{N}$ & Pielou* & Chao*;Pielou** & ns \\
\hline & gene & S & ns & Chao** & Chao**;Pielou* \\
\hline & & $\mathrm{GH}$ & ns & ns & Chao* \\
\hline & & $\mathrm{NxS}$ & ns & Pielou* & ns \\
\hline & & $\mathrm{NxGH}$ & ns & ns & ns \\
\hline & & $\mathrm{SxGH}$ & ns & Chao**;Pielou** $^{* *}$ & ns \\
\hline & & $\mathrm{NxSxGH}$ & ns & ns & Pielou* \\
\hline & 16S rRNA & $\mathrm{N}$ & ns & ns & ns \\
\hline & & $\mathrm{S}$ & ns & ns & Chao*;Pielou* \\
\hline & & $\mathrm{GH}$ & ns & ns & ns \\
\hline & & $\mathrm{NxS}$ & ns & ns & ns \\
\hline & & $\mathrm{NxGH}$ & ns & ns & ns \\
\hline & & $\mathrm{SxGH}$ & ns & ns & ns \\
\hline & & $\mathrm{NxSxGH}$ & ns & ns & ns \\
\hline
\end{tabular}


777 Table 2 Co-variation between taxonomic composition and process data (methane production 778 and oxidation) assessed by fitting the process data onto an ordination derived from a non779 metric multidimensional scaling (NMDS), for every standardized depth (AWT: above the growing season mean water table, WT: around the growing season water table (WT), and BWT: below the growing season mean water table).

\begin{tabular}{lcccc}
\hline Data & $\begin{array}{c}\text { Standardized } \\
\text { depth }\end{array}$ & $\begin{array}{c}\text { NMDS } \\
\text { stress } \\
\text { value }\end{array}$ & R2 & Significance \\
\hline 16S rRNA - $\mathrm{CH}_{4}$ production & AWT & 0.12 & 0.35 & 0.02 \\
& WT & 0.09 & 0.39 & 0.017 \\
& BWT & 0.06 & 0.51 & 0.004 \\
16S rRNA gene -CH 4 & AWT & 0.07 & 0.34 & 0.0026 \\
production & WT & 0.09 & 0.20 & ns \\
& BWT & 0.12 & 0.30 & ns \\
16S rRNA - CH4 oxidation & AWT & 0.12 & 0.33 & ns \\
& WT & 0.09 & 0.01 & ns \\
& BWT & 0.06 & 0.43 & 0.016 \\
16S rRNA gene $-\mathrm{CH}_{4}$ & AWT & 0.07 & 0.05 & ns \\
oxidation & WT & 0.09 & 0.31 & ns \\
& BWT & 0.12 & 0.42 & 0.006 \\
\hline
\end{tabular}

ns denotes non-significant results. 
809
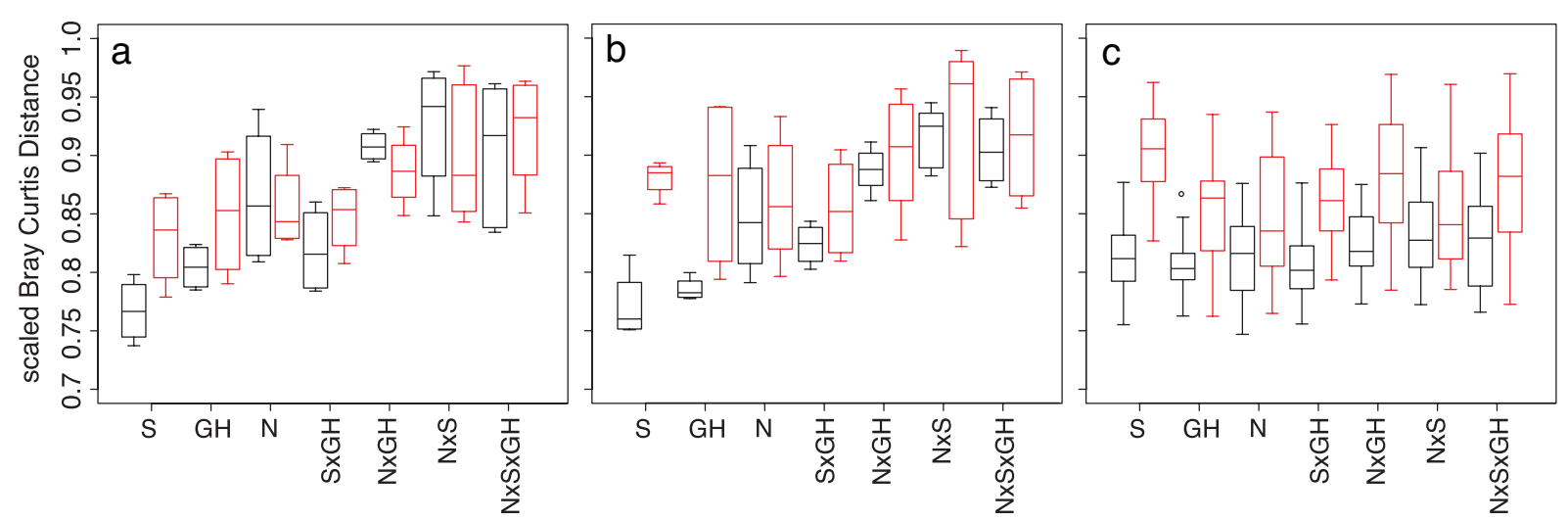

Fig. 1 Prokaryote community composition ( $\beta$-diversity) turnover in relation to the low treatment levels. a: above the growing season mean water table level. $b$ : around the growing season mean water table level. c: below the growing season mean water table level. Black: community composition derived from the 16S rRNA gene. Red: community composition derived from the 16S rRNA. A Bray-Curtis distance of 0 indicates a complete overlap in community composition between the high and low treatment levels, while a Bray-Curtis distance of 1 indicates complete dissimilarity. Note that the scale on the y-axes starts at 0.7. The number of replicates for the main, two- and three-way interaction effects are 8, 4 and 2, respectively. 


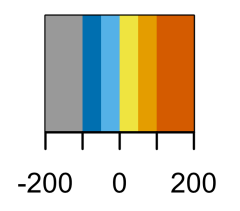

Percentage change

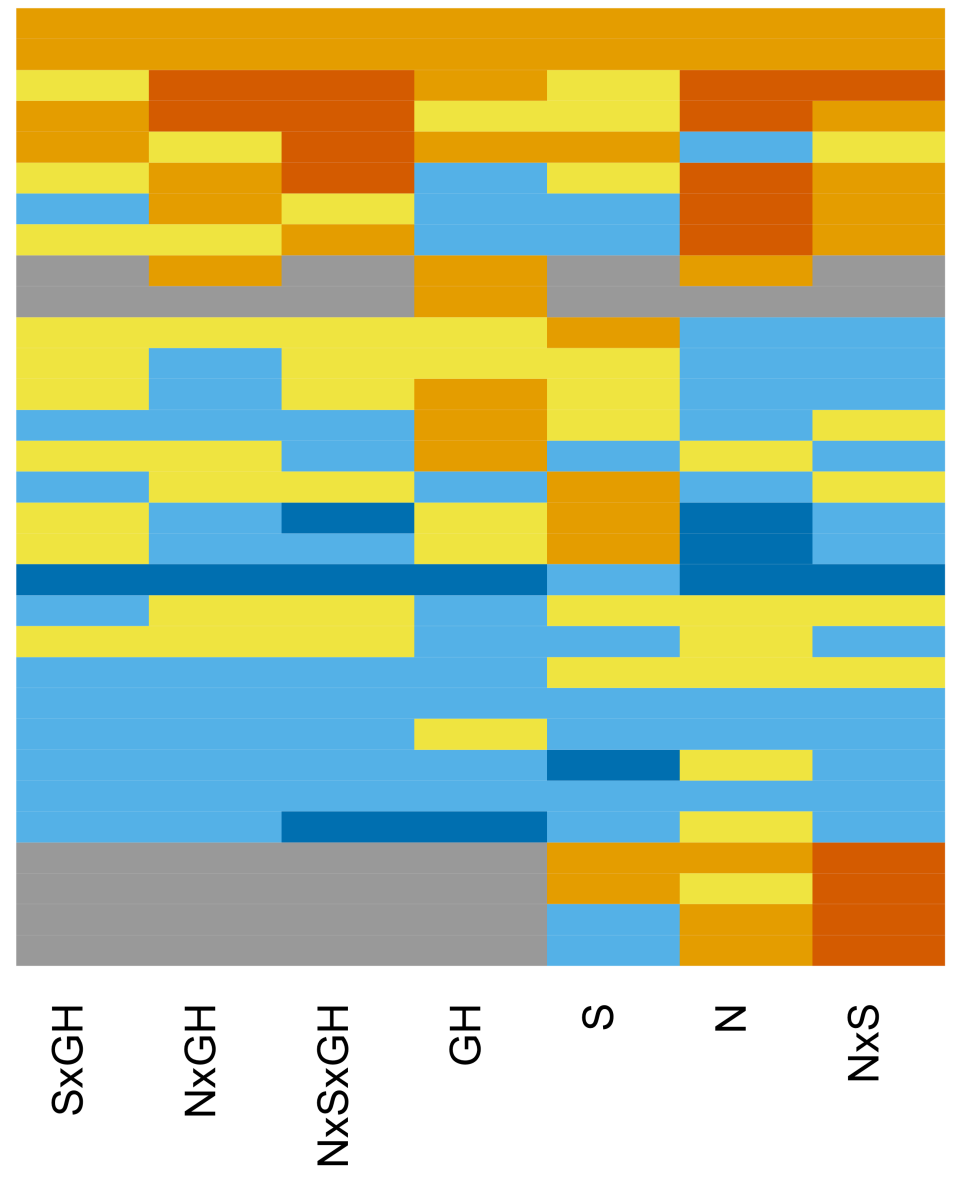

Tenericutes Chlorobi

Euryarchaeota Fibrobacteres BD1-5

Lentisphaerae Chloroflexi Crenarchaeota Dictyoglomi Fusobacteria Candidate division TM6 Chlamydiae Spirochaetes V1

Elusimicrobia Bacteroidetes SM2F11

Planctomycetes Armatimonadetes Proteobacteria Nitrospirae Candidate division OD1 Acidobacteria Cyanobacteria Verrucomicrobia Firmicutes Actinobacteria Thaumarchaeota Candidate division TM7 Deinococcus-Thermus Candidate division BRC1

Fig. 2 Relative change in the abundance of the 16S rRNA-derived phyla comparing the high level and the low level treatments, i.e. the relative abundance of each phylum at the high level was subtracted by the corresponding value for the low level and then divided with the low level value. Grey colour shows the phyla that disappeared with the high level treatment and red colour shows the phyla that appeared with the high level treatment. N, S and GH refer to the main treatment effects of nitrogen, sulfur and greenhouse, and $\mathrm{NxS}, \mathrm{NxGH}$ and $\mathrm{SxGH}$ refer to their two-way interactions, while $\mathrm{NxSxGH}$ represents the three-way combination. 


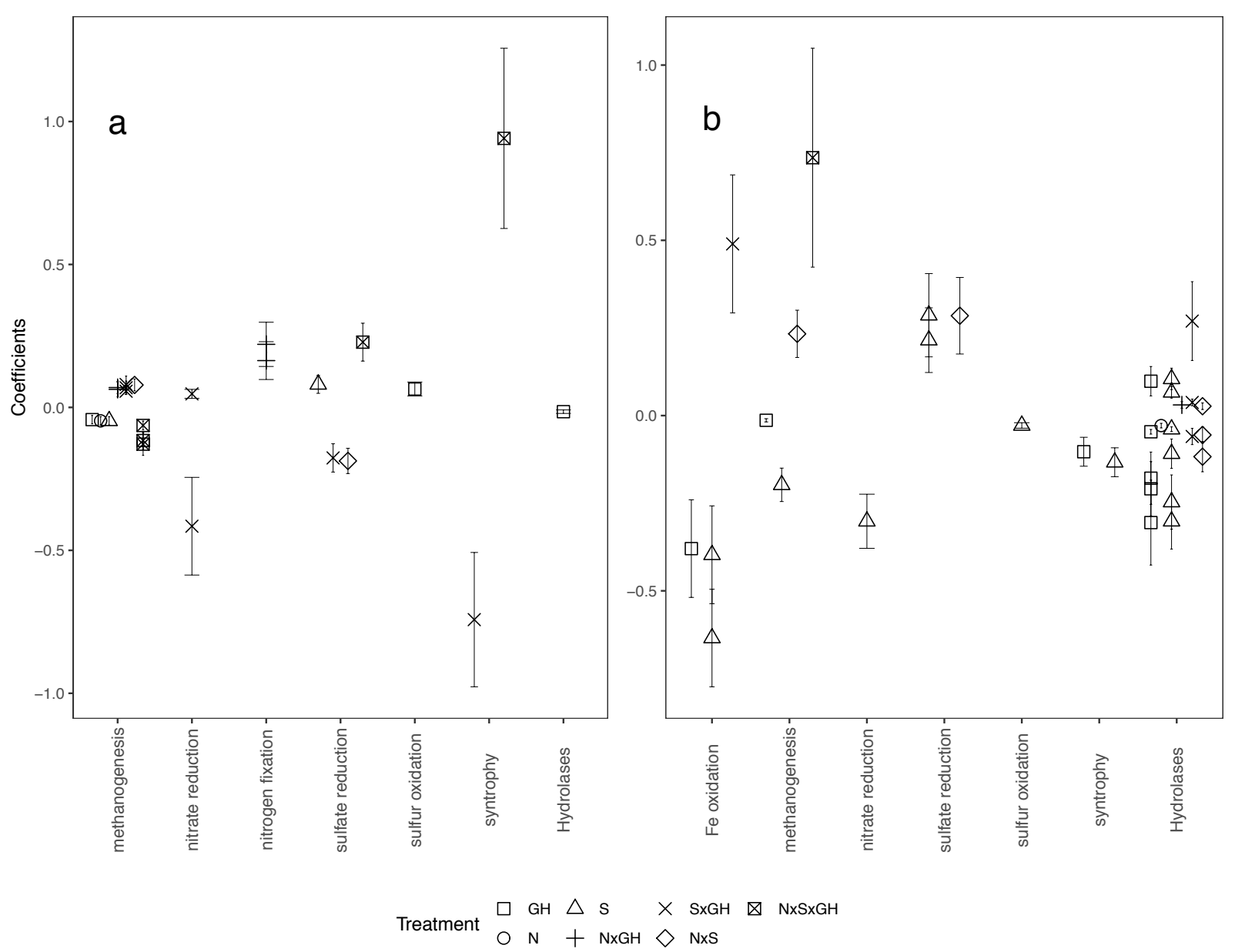

Fig. 3 Generalized linear models (GLMs) on PFAMs (protein families) related to key steps in the anaerobic degradation of organic matter or relevant to the $\mathrm{N}$ and $\mathrm{S}$ cycling, at above the water table (AWT; panel a) and below the water table (BTW; panel b). The treatment responses are indicated by the coefficient, showing a decrease or increase in genome equivalents of each individual key PFAM. Only significant treatments responses are shown. Interaction terms in the regression models and the relationships among the variables in the model should be interpreted in as follows: positive coefficient in the case of interactions indicates a synergistic effect when combining perturbations, while a negative coefficient indicates an antagonistic effect, which can even lead to no expression of the perturbations. 